Francisco Dussuel S. J.

\title{
El creacionismo y la inquietud de lo infinito (1)
}

\author{
Poeta \\ Anti poeta \\ Culto \\ Anti culto \\ Animal metafísico cargado de congojas \\ Animal espontáneo dirccto sangrando sus \\ Solitario como una paradoja \\ [problemas. \\ Paradoja fatal \\ Flor de contradicciones bailando un fox-trot. \\ Sobre el sepulcro de Dios \\ Sobre el bien y el mal \\ Soy un pecho que grita y un cerebro que \\ Soy un temblor de ticrra \\ [sangra. \\ Los sismógrafos señalan mi paso por el \\ [mundo.-"Altazor".
}

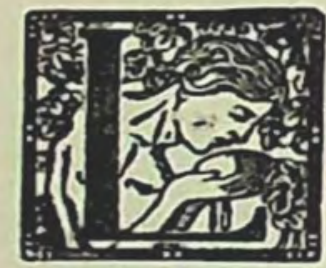

A VOZ de Altazor que se levanta aquí simbolizando la rebeldía, compendia la vida de este poeta, creador superoriginal, que inició su existencia en un hogar de alta alcurnia aristocrática en el que se mezclaban el patriotismo, la fe y el arte. Educado en el Colegio San Ignacio de Santiago, su temperamento indómito choca violentamente con las

(1) Este trabajo corresponde a uno de los capítulos de nuestra próxima obra: La inquictud religiosa en algunos líricos chilenos, 
rígidas normas existentes. Pasando y Pasando (Santiago, 1914), su primer libro en prosa, recoge sus desahogos temperamentales contra algunos de sus maestros. Sin embargo, hemos tenido en nuestras manos Ecos del Alma (1911) en el que hay una sugestiva dedicatoria: "A mi muy querido amigo y a mi muy admirado y respetado profesor de literatura, el sabio y humilde S. J. Rafael Román. Con cariño y admiración.-Vicente García Huidobro Fernández”.

Ecos del Alma recoge las vivencias espirituales y humanas de un joven de dieciocho años. Poéticamente nada tiene de extraordinario. Un ambiente fuertemente romántico satura estas páginas sentimentales, que nos interesan sobre todo por lo que reflejan, ya que veremos al poeta en Adán (1916), o sea, cuatro años más tarde, en abierta contradicción con estos primeros versos sencillos, humildes, tiernamente cristianos y extremadamente románticos.

A los veinte años lo vemos leyendo en el Ateneo de Santiago su manifiesto Non serviam. Es una actitud rebelde, acusadora e incitante, que abomina de la imitación y cifra todas sus esperanzas no en ser esclavo de la naturaleza sino su amo: "Hemos cantado a la naturaleza (cosa que a ella bien poco le importa). Nunca hemos creado realidades propias como ella lo hace o lo hizo cuando era joven y llena de impulsos creadores... Non Serviam. No he de ser tu csclavo, Madre Natura; seré tu amo" (Cf. Antología, Zig-Zag, Santiago de Chile, 1945, páginas 245-246).

La tónica de este "Manifiesto" no sólo comprende una actitud estética. Va mucho más lejos, ya que las nuevas ideas se proyectan destructoras sobre un pasado también familiar y de creencias.

Cedomil Goic en su estudio La poesia de Vicente Huidobro ("Anales de la Universidad de Chile", Santiago, 1956), advierte que la nueva posición de Huidobro (en 1913 ya suprimió el García), se esclarece con algunos datos biográficos que no deben ser subestimados:

"En el mismo año 1914, Huidobro publica un libro de críticas y comentarios: Pasando y Pasando, libro cuya edición fue recogida por el padre del poeta y quemada escrupulosamente. 
En él había desatado Huidobro su juvenil espíritu iconoclasta. Criticaba duramente la educación jesuítica recibida y a sus preceptores ignacianos; lanzaba mordaces juicios sobre sectores de su familia o de su clase; combatía el futurismo, al que consideraba demasiado viejo y hacía un presuntuoso alarde de afirmación individual a pesar de d'Annunzio, el retórico y hueco italiano, cuya vigencia literaria persistía y a quien dos años antes elogiara el poeta, en las páginas de "Musa Joven", 1912".

En otras palabras nos hallamos frente a un joven artista en plena crisis religiosa y en abierta rebelión con todo un pasado.

Ecos del Alma ha quedado ya lejos. Su canto simple va adquiriendo poco a poco estridencias y disonancias que a través de Canciones de la noche (1913), La gruta del silencio (1913) y Las pagodas ocultas (1914), va en busca de la nota íntima, presintiendo la cercanía de lo misterioso y que constituirá un leit motiv característico de su fecunda obra poética.

En La gruta del silencio asoma ya el obscuro caos, que se agita tumultuoso. Lo vemos transformarse en el "pequeño dios" creador de que nos habla en su Arte poética.

\section{EL SIMBOLISMO DE $A D A N$}

La gestación del creacionismo involucra no sólo una concepción estética nueva. Va derechamente encaminada a la "creación absoluta", en la que el poeta no es ya un "pequeño dios", sino la Entidad Absoluta, frente a frente a las fuerzas ocultas, que arranca el misterio de las cosas, para lanzarla a los espacios transformadas en belleza, algo así como el milagro de la energía pura.

El poema Adán (1916) marca en la evolución ideológica de Huidobro un momento decisivo. Auscultarlo desde un ángulo meramente poético, significaría privarlo de todo su contenido de "relación subjetiva", que por ahora es lo que más nos interesa. No es el "Adán bíblico", pero le da "el nombre bíblico de Adán” y no sólo el nom- 
bre ya que el argumento del poema no se diferencia substancialmente de la narración bíblica.

Tres son a nuestro juicio los elementos que creemos esenciales en el análisis conceptual del poema y que se relacionan directamente con nuestro objeto: Silencio, Creación, Cientifismo. El prólogo de Tomás Gabriel Chazal se hace eco del artista al afirmar:

"Antes de llegar hasta Adán - complemento y resumen de inmensa armonía y voz por la que habló la gran meditaciónel poeta se detuvo en el instante en que el Silencio era una enorme sombra sobre la masa que aparecía inerte, porque aún la vida no había hallado el ritmo de la palpitación".

Este Silencio es proceso gestador. Allí está latente la potencialidad inmensa de los seres, capaces en el devenir impetuoso de ir asombrando con sus múltiples maravillas. Silencio fecundo, matriz generadora que el poeta expresa con ímpetu en "El Caos".

La elección de Adán como héroe del poema no es antojadiza. Encarna "la visión del hombre original como el arquetipo de la renovación espiritual y de aquí a un más puro y libre estado de vida humana. Un ser proteico abierto a todas las posibilidades, ubicado en los inicios del mundo en un campo virgen en donde todo comienza" (Goic). Adán realiza el milagro que Hübner anhela para sí, "sorprender - en el alba del mundo las palabras nacientes", con las que continúa la creación, dando nombre a las cosas.

Crear será para él acercarse al lenguaje "del Paraíso"; por eso sólo los que no han olvidado los vagidos del parto universal ni los acentos del mundo recién creado, son poetas. Las células del poeta están amasadas en el primer dolor y guardan el ritmo del primer espasmo".

Dios está ausente en esta concepción del arte. En su poema "Adán" advertimos desde el comienzo su concepción materialista del universo del hombre. Lo invade un frenesí cientifista que Huidobro expresa así en el Prefacio: 
"Tanto me he ceñido a la ciencia que en el canto "Adán ante el mar" puede fácilmente advertirse el origen marino de la vida, que es un fenómeno acuático, según lo ha demostrado hace pocos años M. Quinton y según creen todos los grandes sabios de Europa” (Prefacio, página 22).

Negada la intervención divina en el devenir evolucionista, surge a continuación el sustituto: la interacción de fuerzas físico-químicas, que dirigen todo el mecanismo del cosmos.

Al final de "El Caos", exclama:

surjan $y$ vibren las grandes energias

que duermen sin dormir en su neblina.

Este primer hombre no necesita de Dios.

"Enorme y solo" es el "nuevo creador" que Huidobro sueña. Es el "Adán científico" en oposición al "Adán bíblico", hechura de Dios, de quien recibió el ser y su destino eterno. Huidobro abomina de éstas que él cree "leyendas", capaces de satisfacer las mentes infantiles, pero reñidas con la sabiduría de su "ciencia". Este "Adán” es autónomo y con su sòio esfuerzo penetra los misterios del cosmos, porque la "Madre Naturaleza" lo capacitó para captar las esencias de las cosas. El es el creador. Frente a Adán palpitan los arcanos insondables, los intuye en su virginal pureza y los condensa en paradigmas de original frescura. "Todo lo que veía con santa desnudez se le ofrecía": las aguas amistosas, la clara bondad del cielo, las ramas temblorosas, el cansancio de los pájaros. Era la primera mirada inteligente y buena, que al posarse sobre las cosas, produjo en ellas una emoción acogedora.

Su acto creador no extrae de la nada. Allí tiene ante sus ojos el panorama infinito que espera la plenitud ardiente, la del primer hombre: 


\author{
primer placer de contemplar \\ del escuchar, goce primero, \\ primer placer del admirar \\ $y$ de sentir $y$ del palpar.
}

Lentamente Huidobro va precisando el símbolo. Adán es fuerte, no necesita de Jehová. Posee "la sana alegría del mundo" que nutre sus músculos y siente que su cuerpo está lleno de "luz viva". Todo lo que antes se revolvía multiforme en su obscura conciencia, "toma rasgos precisos y lo llena de santas bendiciones".

Adán no habla aún y cuando lo hace exclama lleno de arrebato:

Entrad en mi, Naturaleza

entrad en mi, joh cosas de la tierra!

Dejad que yo os adquiera

dadme la suprema alegría

de haceros substancia mía.

Todo esto que nace en el suelo

quiero sentirlo dentro.

Huidobro borra de su concepción estética el plano divino del hombre. Lo encierra en su constitución corporal, privándolo así de la eternidad, que él tan vivamente anhela.

Desde este momento el poema se transforma en el fiel intérprete de un Adán más eufórico aún. Cada mirada es un hallazgo, cada palabra es un milagro, creando belleza con los elementos que su "Madre Natura" tan pródigamente le entrega.

\title{
LA INQUIETUD DEL ADAN CIENTIFICO
}

En el desarrollo del héroe, empiezan a surgir los primeros interrogantes. Al silencio, a la meditación siguió la palabra, "impelida por la divina fuerza, que da al cerebro la Belleza”. Adán ante el agua descubre nuevos misterios:

7-Atenea N.० 379 


$$
\begin{aligned}
& Y \text { esto quo se mueve } \\
& \text { ¿a dónde va, de dónde viene? } \\
& Y \text { siguió con los ojos la corriente. }
\end{aligned}
$$

Esta pregunta es el eslabón de una cadena interminable, que se proyectará hasta la incógnita del destino humano.

"Adán ante el Mar" ya da una respuesta. Es la expresión del evolucionismo materialista y ateo, que Huidobro en su Prefacio precisa en esta forma, rechazando toda intervención divina:

"Tanto me he ceñido a la Ciencia que en el Canto "Adán ante el Mar” puede fácilmente advertirse el origen marino de la vida, que es fenómeno acuático..."

Por eso no debe extrañarnos que desde la esencia misma de su ser nazca irresistible "una tendencia al mar". Siente el clamor que viene desde él y que penetra en Adán:

$T \dot{u}$ saliste de mí, tú eres yo mismo

$y$ mis aguas salobres son tu esencia.

Tú eres algo mío, mío más que la tierra, tú, Adán, que ahora me contemplas, que ahora estás en mis orillas escuchando mi música divina.

Huidobro perdió el sentido de las proporciones y su Adán sobrecogido huye a las montañas impulsado por el terror que le inspira el "padre de todos los prodigios".

La inquietud del héroe no se circunscribe sólo a la esfera de lo material. En "Adán va a las Montañas" vemos cómo un interrogante angustioso se le clava en el alma: 
$Y$ de repente surgió en su alma

esta pregunta sola y clara:

¿Y yo por qué estoy aquí?

$Y$ sintió una gran melancolía.

¿De dónde vengo? ¿A dónde voy?

¡Oh primera inquietud de la filosofial

iOh primera amargura

del meditar, primera duda!

El hombre debe ser afirmativo, cantar la vida, huir del pesimismo.

Procedamos con serenidad al escudriñar la densidad del pensamiento huidobriano.

A primera vista parecería que nos encontramos ante una contradicción. ¿No afirmó que el mar es el "padre de todos los prodigios, origen y término de todo el universo?" En esta génesis científica ¿no está incluido el hombre, que ahora se angustia por conocer su origen y su destino final? Lo curioso es que el poeta no permite que su héroe piense y que ahonde en estos interrogantes. "El hombre debe ser afirmativo, cantar la vida, huir del pesimismo". ¿Podrá un Adán "lleno de inquietudes" permanecer tranquilo con esta receta tan simple?

\section{INQUIETUD Y CREACIONISMO}

Huidobro da la respuesta a su "Adán Científico".

Ante todo hay que "huir del pesimismo". Las meditaciones graves, que "estrujan el cerebro buscando el secreto del universo" hay que dejarlas de lado.

Hombre, para llegar a todo

ten más reposo

sé más poeta

deja a un lado tu ansiedad inquieta, 
cierra los ojos ante el sol

- pon en el acto una serena unción-

$y$ después de mirar un largo rato,

verás bajo tus párpados

un continuo girar de átomos.

Y a continuación el poeta declara con énfasis su materialismo absoluto: "Todas las cosas salen de la tierra para volver a ella". Todas, es decir, el universo, las casas lujosas y pobres, los "castillos de cuerpos y de almas",
salen de la tierra
a poner nuevas formas sobre el mundo
a aumentar el tumulto,
a delinear siluctas en el aire
$y$ volver a la tierra alguna tarde.

En este círculo nihilista existe una salida: Crear, prolongar la vida en otros seres, "ser más poeta".

Huidobro desarrolla su idea a través de dos símbolos: Eva y Caín y Abel. Toda creación es fruto del amor. Allí está Eva, la nueva maravilla, un milagro viviente, en medio de los llanos. Como por encanto huyeron las inquietudes ardientes. Nuevas armonías, éxtasis puros, "carne sonrosada y fresca de fruta nueva", ofertorio de vida tumultuosa y fecunda, ola misteriosa de atracción suprema. El instante de excelsa creación se acerca. Nada hay que lo empañe. Laten con vigor las potencias puras, llenas de gracia y fuerza, de belleza y esperanza.

Adán está resignado a su suerte. En Caín y Abel permanecerá su sangre, germinando generaciones.

Huidobro coloca otra vez el lcit motiv del poema, en primer plano: 
Abel, el místico,

Caín es la Ciencia

el puro panteísmo

que no busca las cosas hacia afucra

sino en nosotros mismos.

Por eso es que la ofrenda

continúa el gran símbolo:

la de Cain se esparce por la tierra

y la de Abel sube al vacio.

¿Qué símbolo? El materialismo cientifista y creacionista, que rechaza toda creencia en lo divino. El mismo desarrolla en las estrofas siguientes su pensamiento ateo y el panteísmo naturalista de que hace gala.

Como complemento inserta Huidobro la evocación poética de la Torre de Babel. Es el grito de los hijos de Caín, es el "intento" de un escalamiento gigantesco para derrocar a Dios.

Huidobro sin darse cuenta utiliza un lenguaje muy expresivo para indicar el frustrado esfuerzo de estos primitivos materialistas. La Torre de Babel fue: "intento de un escalamiento gigantesco", "aspiración del mundo todo..." "intento milagroso..." "triunfal monumento... aferrado en las entrañas del vacío...", etc.

Es un buen léxico para condensar el anhelo de los audaces "sepultureros de Dios". Nietzsche y todos sus discípulos, pasando por Huidobro y llegando hasta Sartre, han "intentado", han "aspirado" reconstruir una Babel, que se "aferra en las entrañas del vacío".

\section{INDIVIDUALISMO ATEO}

Huidobro llevaba en sí el germen de un individualismo extremo. Reacio a toda norma establecida rompe con verdadera exaltación iconoclasta la tradición familiar, sin detenerse tampoco en los prin- 
cipios religiosos católicos, que como ya vimos, fueron rectores de sus años juveniles.

La crisis espiritual que desemboca en el ateísmo debe haber sido rápida.

El mismo nos narra en Manifestes al explicar el Creacionismo que Adán fue escrito en las vacaciones de 1914 y publicado en 1916. Sabemos por otro lado que Ecos del alma apareció en 1911. De todos modos la resultante final de esta desintegración espiritual fue la pérdida de la fe en Dios y la substitución consciente por la Ciencia. Es el sentido del poema Adán.

Intencionadamente colocamos "Individualismo ateo" para indicar una peculiaridad de Huidobro. No todo individualismo desemboca necesariamente en la negación de Dios. A veces adquiere matices "antidogmáticos" como en Magallanes, para elaborar luego un "Dios Idea" o "Sentimiento", divinidad vaga que se diluye también en un "panteísmo", al estilo de Daniel de la Vega.

El "mito creacionista", analizado tan magníficamente por Cedomil Goic en la obra ya citada, hay que considerarlo desde dos ángulos diferentes: como fenómeno literario y como vivencia ideológica. Las nítidas aproximaciones bíblicas que encierra nos hablan de un "sentido teológico", despojado de toda relación divina y trasladado al plano "creacionista".

El elemento inspirador de la vida, la palabra eterna de Dios que crea con su poder, es substituido por la poesía. Ella opera la maravilla de "poner cosas en el ser por la palabra". Por eso el poeta creacionista es un "pequeño Dios", que "seculariza sus símbolos", "sin comulgar con su intimo sentido religioso" (Goic, página 92). Con razón Eduardo Anguita, en la Antología de Vicente Huidobro, lo llama "especie de San Juan de la Cruz" "ateo" (Zig-Zag, 1945, página 21), expresión que condensa una posición ideológica exacta.

"Las siete palabras del poeta" constituyen una confirmación de lo que estamos diciendo. Utiliza como símbolo el drama del Calvario, lo despoja de su contenido sobrenatural y lo encadena a la expresión de su "yo". 
"Desde lo alto de mi cruz, plantada sobre las nubes y más esbelta que el avión lanzado a la fatiga de los astros, voy a arrojar sobre la tierra mis siete palabras, más cálidas que las plumas de un pájaro fulminado".

Eduardo Anguita transcribe en su Antología (página 247) un fragmento de una conferencia leída en el Ateneo de Madrid el año 1921. Huidobro expone su pensamiento acerca de la poesía. Aquí salta a la vista la "aproximación bíblica", desprendida de toda proyección divina.

La poesía es "vocablo virgen de todo prejuicio", encarna la esencia del "verbo creado y creador, la palabra recién nacida". "Ella se desarrolla en el alba primera del mundo" (Anguita, página 247).

No se necesita violentar el texto para ver la íntima relación de este trozo con el capítulo primero del Evangelio de San Juan, guardando, claro está, la enorme distancia que los separa y contrapone. Prosigue:

"su vocabulario es infinito... Para ella no hay pasado ni futuro. El poeta crea fuera del mundo que existe el que debiera existir. Yo tengo derecho a querer ver una flor que anda o un rebaño de ovejas atravesando el arco iris y el que quiera negarme este derecho o limitar el campo de mis visiones debe ser considerado un simple inepto".

"La Poesía está antes del principio del hombre y después del fin del hombre. Ella es el lenguaje del Paraíso y el lenguaje del Juicio Final, ella ordeña las ubres de la eternidad, ella es tangible como el tabú del cielo".

"La Poesía es el lenguaje de la Creación. Por eso sólo los que llevan el recuerdo de aquel tiempo, sólo los que no han olvidado los vagidos del parto universal, ni los acentos del mundo en su formación son poetas...". 
Altazor se erguirá más tarde "sobre el sepulcro de Dios". A Huidobro le basta esta divinidad que él ha concebido: "el poeta es un pequeño dios".

Así ha llegado a la substitución del Dios Creador, que en nada se opone a su "Creacionismo", pero que no tiene cabida en su alma. Esta voluntad de volver a la "fuente matriz" de las cosas para poder lanzar a pulmón lleno el "Fiat lux que lleva clavado en su lengua", satisface las inquietudes de su alma ya que así descubre los secretos del mundo $y$, puede extender la mano para conducir a los demás:

más allá de lo verdadero y lo falso, más allá de la vida y de la muerte, más allá del espacio $y$ del tiempo, más allá de la razón y la fantasía, más allá del espíritu y la materia.

Más de alguna vez hemos pensado al leer trozos parecidos, que Huidobro en su exaltación creadora perdió no sólo el sentido de las proporciones sino también la capacidad de relacionar ideas. La hipérbole es un recurso poético que dosificado es capaz de crear belleza, pero lanzada en carrera desbocada se transforma en disloque subjetivista.

Claro está que Huidobro podría respondernos: "El que no haya sentido el drama que se juega entre la cosa y la palabra, no podrá comprenderme" (op. cit., página 249).

Esta "divinización de la poesía" que estamos comentando le hace exclamar en el prólogo a Defensa del ídolo, de Luis Omar Cáceres, en 1924:

"La poesía está en todas partes (como decían antes de Dios). La Poesía es. La Poesía forma parte del ser universal, es su esencia misma y por eso sólo los poetas conocen los hilos que unen las cosas. Las fuentes de la poesía son las mismas fuentes de la energía universal. El poder creador, el poder 
transformador. Su historia es el más perfecto historial de la Naturaleza y del hombre" (cita de Goic, página 128).

Como podrá observarse, el "pequeño dios" del Arte Poética ha ido lentamente tomando proyecciones insospechadas. Se ha transformado en un ser autónomo, poseedor de un poder omnipotente, omnisciente y omnipresente. En otras palabras, en el "hombre dios" que aparece ya precisado en Saisons Choisies.

Huidobro desarrolla su pensamiento en torno a la "creación pu$r a$ ". Este "ensayo de estética" aparecido en 1921, permite al poeta lucubrar y precisar su concepción del arte.

Existen según él, tres fases o aspectos que pueden ser esquematizados así: Arte inferior al medio (arte reproductivo). Arte en equilibrio con el medio (arte de adaptación). Arte superior al medio (arte de creación).

Más adelante entra ya de lleno en el tema que nos interesa:

"toda historia del arte no es más que la historia de la evolución del hombre espejo hacia el hombre dios y estudiando esta evolución se veía claramente la tendencia natural del arte a desligarse cada vez más de la realidad preexistente para buscar su propia verdad dejando a la zaga todo lo superfluo y todo lo que pudiera perjudicar su realización perfecta".

Hombre Espejo-Hombre Dios, he aquí el comienzo y fin de una evolución artista. El "hombre espejo" copia, calca, remeda imperfectamente e imita desvirtuando la Naturaleza. El mismo se empequeñece, voluntariamente se encierra en una cárcel prefabricada, que amordaza sus impulsos y se autotransforma en un reproductor contrahecho, marginándose de la exuberante prodigalidad que lo rodea. Es digno de lástima. El mismo es causa de su destrucción. Jamás llegará a la creación perfecta.

El "Hombre dios", el "artista creador absoluto", el "artista dios" 
le fue sugerido "por un viejo poeta indigena de la América del Sur (aymará), que dice":

"El poeta es un dios; no cantes la lluvia, poeta, haz llover. Aunque el autor de estos versos cayera en el error de confundir al poeta con el mago y de creer que el artista, para mostrarse creador, debe trastornar las leyes del mundo; cuando en verdad, lo que debe hacer es crear su mundo propio e independiente paralelamente a la naturaleza”.

Huidobro ha esclarecido aquí con luz meridiana su pensamiento. De un lado la negación del Dios Absoluto, Ser Eterno e Infinito, Creador del Universo y substitución por la Madre Naturaleza, la misma que en Adán fuera ensalzada como "padre de todos los prodigios - origen y término - de todo el Universo". Es la afirmación del materialismo naturalista y ateo, creador fecundo de todas las maravillas. Alude a la exclusiva interacción de las fuerzas físico-químicas. Reaparece el contenido ideológico del Adán Científico. Frente a la "Madre Naturaleza", creadora deslumbrante, se yergue el "hombredios". El poeta debe imitarla, no copiando las maravillas que ella ha producido, sino "creando" también nuevas bellezas. Es la "imitación" de su "poder creativo".

Reconocemos en esta original y audaz concepción del arte un anhelo sincero de un inmenso artista. Pero ¿se oponen "Creacionismo" y la fe en el Dios de sus primeros años? No.

Podrían perfectamente coexistir. Lo trágico en Huidobro es que su concepción estética surgió después de la crisis espiritual que lo azotó. Tal vez, o mejor dicho, sin lugar a dudas, las geniales intuiciones que nos legara como testamento, habrían adquirido proyecciones insospechadas si la Divinidad interviniese en sus ideas. ¡Misterios insondables!

Analizando la esencia misma del "Creacionismo" nada hemos hallado que nos contradiga. Lo que él pretende es captar la esencia de las cosas en su primitiva pureza, en la "fuente misma de los seres". 
En íntima consonancia con Schleirermacher afirma "que la poesía no busca la verdad que no ticne nada de común con la verdad objetiva" (cita de Huidobro en Saisons Choisies).

Es una aspiración legítima de un artista, luchando por liberarse de lo externo, deseando así crear su mundo propio de vivencias. Es un "antropocentrismo no absoluto", ya que las cosas existen fuera de él. La creación se condensará más bien en las nuevas relaciones, en los "lazos sutiles que se tienden las cosas entre si", en "las voces secretas que se lanzan unas a otras palabras separadas por distancias inconmensurables", en el "darse la mano" vocablos enemigos desde el principio del mundo y en el "genio recóndito de las palabras", con un pasado mágico que sólo el poeta sabe descubrir, porquo él siempre vuelve a la fucnte" (Temblor de Tierra).

Esta concepción del arte que si fuera realizable en su plenitud engrandecería al artista, ¿debe estar reñida con un Dios Personal, Eterno y Creador? ¿Por qué? El poeta quiere despojar al "verbo creador" de todo lo que el tiempo, los convencionalismos humanos, las pasiones y los intereses dejaron en él como escoria repudiable. Es la "verdad de la vida y la verdad del arte" diferenciándose para caer en el "arte y poesía que expresen solamente la verdad de la conciencia singular", como dice Schleirermacher (Aestetik, páginas 55-61, cita de Huidobro).

Es la misma idea que se expresa en "Sátiro o el Poder de las Palabras", desconcertante novela aparecida en 1939.

Bernardo Saguen hojea un libro de Rimbaud. La Poesía del "joven genio" "estalla como una estrella" al fondo de su espíritu. Se quedó meditabundo y como en éxtasis: "La Poesía... es el pensamiento y el pensamiento en estado puro. La poesía es una facilidad de pureza, una tendencia del espíritu a olvidar los compromisos que ensucian nuestra voz" (página 16).

$\mathrm{Y}$ al dialogar más adelante con su amigo Mario Viner, Saguen, "el sátiro", misántropo y misterioso en su psiquis, llena de complejas estructuras, vuelve sobre el tema: 
"¿A qué realidad? ¿Cuál es la realidad? El poeta es el único que la conoce y todos creen, al revés, que es el único que la ignora. El poeta suscita la realidad, no acepta cualquier realidad, sino aquella que resuena en el plano de su espíritu. Va por el mundo creando realidades, porque las cosas más apartadas, más grandes, más pequeñas, más escondidas se dan la mano ante sus ojos” (op. cit., Zig-Zag, 1939, página 20).

La "concepción creacionista" de Huidobro ganaría en belleza, llegaría a ser deslumbrante si estas dos fuerzas creadoras no fueran la del poeta y la de la naturaleza, sino la de aquél y la de Dios. Huidobro no comprendió como Gabriela Mistral el sentido religioso de la creación. Para ella la naturaleza es el "sueño de Dios", la concepción genial del Eterno Artífice. Por eso exclama en su Decálogo del Artista:

"No hay arte ateo. Aunque no ames al Creador, lo afirmarás creando a su semejanza".

Lo que podríamos llamar la otra cara de la medalla creacionista, el naturalismo, empobrece el conjunto restándole trascendencia. Con insistencia casi majadera repite que el "hombre pertenece a la Natu. raleza", que es "producto de la Naturaleza" y que debe seguir "las leyes de la Naturaleza".

¡Cómo se iluminaría el horizonte si todo esto se proyectara a las divinas y sublimes visiones de Dios, fuente de la vida, Verbo Creador, manantial perenne de belleza pura, armonía de los cielos, presencia viva, resplandor eterno! ¡Qué opaca y tenebrosa es poéticamente una Naturaleza sin inteligencia y sin amor! Una interacción permanente y fortuita de fuerzas físico-químicas no pueden suplantar a Dios del plano creacionista.

Muy lejos nos llevaría el planteamiento del problema filosófico que aquí se anida.

Altazor nos dará en parte la respuesta. 


\section{LA ANGUSTIA DE LO INFINITO}

He aquí la síntesis de este problema gigantesco que se llama Altazor.

Huidobro lo fue dando a luz fragmentariamente, hasta que en 1931 se publicó en Madrid.

Doce años duró la gestación dolorosa de esta obra, que para Goic es "la más notable del creacionismo" "y una pieza poética singularísima en la literatura universal; poema complejo y cargado de humanidad, es uno de los que acusa con mayor acierto y profundidad la calidad del hombre de nuestro tiempo.

"Altazor" es una de las expresiones más extraordinarias de una cultura cimentada en un humanismo antropocéntrico y materialista" (op. cit., página 204).

Vamos a prescindir de la técnica creacionista para concentrarnos más bien en lo que constituye nuestro objetivo: el mensaje de su espíritu.

Quien audazmente se haya atrevido a internarse en la enmarañada selva huidobriana, sembrada de dinamitas que explotan bajo cada pisada, habrá advertido que su "creacionismo" supera las aspiraciones humanas.

Llegar a realizar este milagro estético es prácticamente imposible.

El mismo poeta nos recuerda en Manifestes, citado por Anguita en su Antología (página 260), un hecho que nos coloca en la huella. En una comida íntima el profesor argentino José Ingenieros, que había asistido a la conferencia que diera Huidobro en el "Ateneo de Buenos Aires", en junio de 1916, expresó sus temores al artista. El poeta "creacionista" recuerda que ese día fue bautizado poéticamente. Después de afirmar que "la primera condición de un poeta era crear, la segunda crear y la tercera crear", flotó en el ambiente un nombre exacto para el conferenciante: "creacionista". Pues bien, el doctor Ingenieros habló en estos términos: 
"Su sueño de una poesía inventada en todas sus piezas por los poetas me parece irrealizable, aunque Ud. la haya expuesto de una manera tan clara y aún científica" (Anguita, página 260).

Huidobro responde al Dr. Ingenieros, a "otros filósofos en Alemania y demás países en donde he explicado mi teoría":

"Si el hombre ha sometido los tres reinos de la naturaleza, el mineral, el vegetal y el animal, ¿por qué razón le sería imposible agregar a los reinos del mundo, su propio reino, el reino de sus creaciones? (Anguita, página 260).

Ante todo procedamos con serenidad. ¿Sometió en realidad el hombre los tres reinos? ¿No es él un vasallo, a quien escasamente le es concedido ir descubriendo misterios que cada vez son más maravillosos? ¿Por qué los encuentra? ¿Es el amo y señor o no es más bien una víctima?

En segundo lugar ¿¿el reino de sus creaciones" es realizable en su plenitud?

Su concepción creacionista, la de ese "pequeño dios", ¿no es objetivo fuera de su alcance, tal como él la concibe?

¿Será posible que el poeta llegue a desnudarse tan sustancialmente de todas las vivencias que lo aprisionan, de los factores biológicos, hereditarios, climatéricos y de educación?

¿No será una mera ilusión todo ese mundo soñado y ambicionado de la verdad pura, del verbo creador, desligado, absolutamente de toda otra realidad que la de él mismo?

Ese "crear situaciones extraordinarias, como exige on "Manifestes", que nunca podrán existir en la realidad, y a causa de esto, ellas deben existir en el poema, a fin de que existan en alguna parte", ¿es una meta posible en cada instante o es un anhelo en una noche de verano?

Huidobro afirma. Altazor se angustia. 
Y por una de esas paradojas amargas, la creación del poeta traiciona al artista que la concibió.

Altazor tiene sobrada razón para vivir atormentado. Huidobro le construyó el lugar de su tormento.

¿Por qué?

\section{EL CREACIONISMO ES UNA META IMPOSIBLE}

Existencialismo $y$ creacionismo se entrelazan sin pretenderlo en un punto de contacto: la angustia de vivir sin llegar al fin inalcanzable, que se anhela con todas las vivencias del ser.

He ahí, a nuestro juicio, la primera causa:

"Un cracionismo imposible, hermoso como concepción estética, pero "monstruoso" para el hombre, ya que escapa a sus limitadas posibilidades.

El "pequeño dios" debería ser Dios para abarcarlo en su plenitud. Y no lo es. Más aún: nơ puede serlo.

En segundo lugar existe en este "mundo antropocéntrico ateo" un vacío que el hombre no puede soportar: la ausencia del amor.

Encadena Huidobro irremisiblemente al artista y lo circunscribe a la esfera material, fríamente científica en donde se conjugan leyes naturales sin otra razón de ser que "ser ley".

$\mathrm{Y}$ el creador de belleza debe imitar a la Naturaleza en esa potencia inventiva.

Nos complacemos en transcribir las palabras de Eduardo Anguita por creerlas exactas y en plena concordancia con nuestro punto de vista:

"Huidobro no ama al mundo como es: primero lo limpió con sus sentidos de niño; luego al propio mundo creado por él en su poesía. No le insufló amor: como un padre que sólo se contentara con procrear hijos, y no les diera sustento: quedando en última instancia con un soio resultado, que parece ser la esencia de su poética: el acto de crear, el ejercicio deses- 
perado de inventar, de probarse y contemplarse a sí mismo en la virtud creadora. Con esto, la obra creada, como resultado, logra un aspecto verdaderamente demoníaco: pues, maravillosa de inventiva, de cantidad y diversidad de hallazgos, carece de afección amorosa, lo que la hace aparecer tan rica y pobre, tan grandiosa y desamparada, a la vez del amor de Dios" (Vicente Huidobro, El Creador, "Estudio preliminar de su antología”, página 29).

En Saisons Choisies, Huidobro parecería contradecirnos. Al establecer la triple división que ausculta en la evolución histórica del arte (arte de reproducción, de equilibrio, con la adaptación al medio y de creación, superior al medio que lo rodea), establece a continuación otro esquema:

a) Arte de reproducción: predominio de la inteligencia sobre la sensibilidad.

b) Arte de adaptación: equilibrio de la sensibilidad y de la inteligencia.

c) Arte de creación: predominio de la sensibilidad sobre la inteligencia.

"Este predominio de la sensibilidad sobre la inteligencia", que reserva como elemento esencial para el "Arte de creación", está encaminado en Huidobro no hacia el corazón, sino que contempla más bien la capacidad o mejor la perceptibilidad intuitiva, rauda, ágil y penetrante que se necesita en el creacionismo.

A través de sus resortes maravillosos conocerá el poeta " $c$ eco de los llamados de las cosas a las palabras, verá los lazos sutiles que se tionden las cosas entre sí, oirá las voces secretas que se lanzan unas a otras palabras separadas por distancias inconmensurables" (De Temblor de cielo, cita de Anguita, Antología, página 249).

La inteligencia queda así supeditada a la sensibilidad artística. Esta es la que dirige con su instinto de lo bello la búsqueda de las relaciones ocultas. Es la dínamo poderosa que arrastra a todo el ser, pero se satisface éste con una especie de "narcisismo intelectual" en el 
que está ausente el amor, para ser substituido por la satisfacción de haber realizado algo nuevo y bello "no porque evoque cosas que se han visto y que cran bellas... sino porque le confiere una vida propia", que existe sólo en el creador.

"Cuando yo escribo: "El pájaro anidado en el arco iris" os presento un fenómeno nuevo, una cosa que nunca habéis visto, que no veréis jamás y que, sin embargo, os gustaría ver. "Un poeta debe decir esas cosas que sin él jamás serían dichas" (Manifestes, Antología, página 261).

Este "maníaco de la invención" como lo llamó Alfred Homes va tras lo "nuevo bello", impelido por su sensibilidad, que somete a la razón, pero permanece frío, marmóreo, al privado de ese calor íntimo, fecundo y necesario, que es exigido por la naturaleza misma del hombre.

\section{LA BUSQUEDA}

Encarna "Altazor" el "peregrino de lo absoluto", el ansia incontenible de lo infinito, de lo inmutable, que atormenta al hombre contemporáneo, espectador impotente de la destrucción en masa, del derrumbe de ideales y del caos en que se precipita la raza humana. Una forma de evasión: "proyectarse hacia lo infinito".

"Altazor" es un nombre simbólico. "Alto" sumado a "Azor". Huidobro dice: "Aqui yace Altazor, azor, fulminado por la altura". Son siete cantos con acordes y armonías elegíacas, aunque el "superhombre" parezca tomar la delantera para ocultar el rictus de amargura que ofrece su rostro.

A pesar del "creacionismo", hermético en muchos fragmentos, se siente de cerca un drama interior, amargo y tormentoso, atravesado por dudas y trizamientos del alma, cuyos sonidos sordos, lentos y repetidos, indican cómo se desploman los cimientos de su mundo interior. 
Nos llegan quejidos de un nuevo alumbramiento en el que florece la nada, el vacío, y "la nebulosa de la angustia que pasa como un rio".

Un "¿ángel malo se paró en la puerta de tu sonrisa" y "con la espada en la mano - sembró la angustia en la llanura de tus - ojos como el adorno de un dios?"

Vuelve otra vez la relación bíblica, pero desnuda de esos acentos deslumbrantes y vigorosos del "Adán Científico".

Goic anota con profundidad:

"Este canto (el primero) se inicia con una nota extraordinaria de lo que podríamos llamar encuesta existencial de nuestra época en esa concepción eminentemente heideggeriana del hombre abandonado a sí mismo. En ella aparece esa revelación patética de la existencia, que es posible encontrar en los grandes preocupados de la existencia” (Goic, op. cit., pág. 206).

La universalidad de "Altazor" comprende, pues, no sólo el hombre contemporáneo sino a todo aquel que esté "soio en medio del universo" - "solo como una nota que florece en las alturas del vacio". Cuando hicimos el análisis de Adán anotamos la importancia que daba el poeta a la "soledad" y al "Silencio". De nuevo esta especie de leit motiv insistente en todos los "solitarios". Pero allá en Adán es un "silencio, una "Soledad" en medio de la noche, del "caos" y de la "inercia preñada de futuras fuerzas". Es un "silencio expectante" que irrumpirá más tarde en un himno a la Naturaleza, cuando ésta desencadene "las ansias oprimidas" y la "revolución de gérmenes" estalle en "anuncios de simientes". De ahí que "El himno al Sol", la "anhelante miraia hacia el futuro" que aparece en "Caos", se ilumine y sea "sublime soledad - soledad de grandeza - soledad de ser sol".

Toda el "ansia de ser", de vivir y de identificarse con la Naturaleza de "Adán", ha sufrido un cambio total. El llamado que hace el poeta en los primeros versos del Canto I a su héroe define una situación existencial absolutamente antagónica a la de "Adán": 
“Altazor, ¿por qué perdiste tu primera serenidad? ¿Qué ángel malo se paró en la puerta de tu sonrisa con la espada en la mano? ¿Quién sembró la angustia en la llanura de tus ojos como el adorno de un dios? ¿Por qué un día de repente sentiste el terror de ser? ¿Y esa voz que te gritó vives y no te ves vivir? ¿Quién hizo converger tus pensamientos al cruce de todos los vientos del dolor? Se rompió el diamante de tus sueños en un mar de estupor. Estás perdido, Altazor. Sölo en medio del Universo. Solo como una nota que florece en las alturas del vacío. No hay bien, no hay mal ni verdad ni orden ni belleza. ¿En dónde estás, Altazor?”

El patetismo de este "preludio tenebroso" es profundo porque se proyecta hasta los interrogantes más trascendentales. No existe la serenidad, la angustia lo consume, el "terror de ser" lo espanta, el dolor absurdo se cruza en su camino, ideales destrozados, soledad en medio de un Universo habitado.

Es el esquema de un existencialismo ateo, que busca la altura y cae aniquilado por lo "absurdo" y lo "angustioso" de la vida, que produce "náuseas", como en Jean Paul Sartre.

No nos debe extrañar entonces ese verso rebelde y profundamente dramático:

No hay bien, no hay mal ni verdad ni orden ni belleza...

¡Qué total debe haber sido la hecatombe cuando el padre del "creacionismo" niegue hasta la belleza!...

Esta cadena de negaciones nos hace pensar en Heidegger, que construyó también todo su sistema filosófico al margen de Dios, aunque no hiciera nunca profesión de ateísmo. ¿Qué es el hombre según él?

"Seres de la nada, que vienen de la nada y que van a la nada, sin poder aferrarse a nada que los pueda salvar" (Jean 
Marie Grevillot, Las grandes corrientes del Pensamiento Contemporáneo, Zig-Zag, 1955).

Este "terror de ser" se acerca mucho también al contenido filosófico de "Etre et Neant" de Sartre que culmina en la "angustia existencial, mezcla de "absurdo" y "náusea".

Huidobro está planteando un problema trascendental que enraiza en el sentido de la vida, problema esencial al hombre, ardiente interrogante de la filosofía, del arte y de la historia.

"Altazor" indica su nacimiento: "Nací a los treinta y tres años, el día de la muerte de Cristo: nací en el Equinoccio bajo las hortensias y los aeroplanos del calor". Recordemos que estamos en plena realización creacionista.

Goic ve en esto la afirmación nietzscheana del "anticristo". Es bien sugestiva la fecha, pues, Altazor nace cuando muere Cristo.

Huidobro traza más adelante un cuadro impresionante de lo que él concibe como el fracaso del cristianismo. Perdida la fe no se puede comprender la misión sobrenatural de la Iglesia. Proyecta sobre ella su visión naturalista de las cosas y exclama:

Morirá el cristianismo que no ha resultado ningún problema.

Que sólo ha enseñado plegarias muertas.

Muere después de dos mil años de existencia.

Un cañoneo enorme pone punto final a la era cristiana.

El Cristo quiere morir acompañado de millones de almas.

Hundirse con sus templos.

$Y$ atravesar la muerte con un cortejo inmenso.

Mil aeroplanos saludan la nueva era.

Ellos son los oráculos $y$ las banderas.

Estas altisonantes afirmaciones nos traen a la memoria los ataques al cristianismo que abundan en Así habló Zaratustra. Son variaciones de un mismo tema, con ampulosa y estridente orquestación moderna. ¡Qué lejos estamos de Ecos del Almal: 
$Y$ cuando en mi agonía ticmble de frío

Nadic te aparte, nadie de mi mirada.

Llevarte entre mis manos es lo que ansio.

A la postrera, eterna, feliz morada.

("Mi crucifijo").

"Altazor" no tiene soluciones capaces de liberarlo.

Vive con la "nebulosa de la angustia que pasa como un rio", y siente cerca de sí "la cola de un cometa me azota el rostro y pasa relleno de eternidad".

Pero Altazor busca con afán, indaga y anhela un remanso que lo aquiete:

Buscando infatigable un lago quieto en donde refrescar su tarea ineludible.

\section{Y DE PRONTO EL TEMA DE LA MUERTE}

Ya en el Prefacio está anunciada como el aniquilamiento definitivo, tumba de la inutilidad de los esfuerzos:

"Mi paracaídas empezó a caer vertiginosamente. Tal es la fuerza de la atracción de la muerte y del sepulcro abierto. Podéis creerlo, la tumba tiene más poder que los ojos de la amada. La tumba abierta con todas sus imágenes. $Y$ esto te lo digo a ti, a ti que cuando sonríes haces pensar en el comienzo del mundo.

"Mi paracaídas se enredó en una estrella apagada que seguía su órbita concienzudamente, como si ignorara la inutilidad de sus esfuerzos".

Huidobro simboliza en el paracaídas que desciende "arrastrado según la ley de las atracciones", el "ser para la muerte" de que nos habla Heidegger y con él todos sus seguidores. 
Nada más desconsolador que la visión terminal del hombre, ofrecida por el existencialismo. Propicia el "nihilismo", vacío en el que se denigra el todo.

El Poeta se lo recuerda a "Altazor":

Cae

Cae eternamente

Cae al fondo del infinito

Cae al fondo del tiempo

Cac al fondo de ti mismo

Cae lo más bajo que se puede caer

Cae sin vértigo

A través de todos los espacios y todas las edades.

Esta "caída" sigue obsesionando al poeta. Lo ve pasar a través de la infancia y la vejez, las lágrimas y las risas, de la cabeza a los pies, dēl mar a la fuente.

El "caos" tenebroso espera con sus frases hambrientas:

Cae el último abismo del silencio

Como un barco que sc hunde apagando sus luces.

La "soledad" de "Adán", esperando el milagro de la vida y del amor, se ha transformado en la "soledad" de Altazor, que marcha en línea recta hacia "la nada":

Estás solo

Y vas a la muerte derecho como un

iceberg que se desprende del polo.

"Altazor" será capaz de hallar alguna solución, o mejor, Huidobro ¿le propone alguna evasión a este callejón sin salida?

Existe en el Canto I una marcada tendencia de ascensión espiritual, que para algunos críticos se encarna en esta especie de "salto 
hacia el infinito" "con proyecciones cósmicas". Goic ve "la nostalgia de Dios” (página 209).

Así es en verdad. El "infinito" de que aquí se nos habla es una entidad vaga, casi más bien una "aspiración", un deseo de "eternizarse", él, Altazor.

Sólo en muy pocas partes se insinúa un "ser personal" con caracteres semejantes al Dios Creador, Eterno e Infinito, El que Es por esencia, El que posee la plenitud del ser, capaz de acallar las existenciales exigencias de Altazor.

Este sueña en "un ser materno donde se duerma el corazón - un lecho a la sombra del torbellino de enigmas - Una mano que acaricie los latidos de la fiebre".

Allí radica toda la intensidad del drama, cuyo desenlace "nihilista" pretende evadir. Adán se eterniza en sus hijos, Huidobro en la creación pura, pero ¿Altazor? Prendido en los barrotes de su cárcel materialista, exclama:

Vivir, vivir en tinieblas

Entre cadenas de anhelos tiránicos collares de gemidos

$Y$ un eterno viajar en los adentros de sí mismo

Con dolor sin limites constantes y vergüenza de ángel estropeado Burla de un dios nocturno

Rodar rodar rotas las antenas en medio del espacio

Entre mares alados $y$ amores estancados.

Citamos anteriormente un texto de "Altazor" en el que afirma enfáticamente: "Morirá el cristianismo que no ha resultado ningún problema".

Millones de seres podrían afirmar lo contrario, pero nos interesa esta posición para comprender que Jesucristo nada significa para él, a pesar de las ideas expresadas en "Pasión, Pasión y Muerte", poema incrédulo, escéptico y de tonalidad poética hondamente humana, publicado en Santiago de Chile con ocasión de la Semana Santa de 1926. Esta postrera "agonía del cristianismo", que difiere de Miguel de 
Unamuno, es anunciada con "un cañoneo enorme". Una "nueva era" se levanta en el Oriente, a los resplandores de la "ciencia moderna":

Mil aeroplanos saludan la nueva era
Ellos son los oráculos y las banderas.

El creador del Adán Científico ya no cree en la "Ciencia" como solución a las angustias existenciales.

Esos "mil aeroplanos, oráculos y banderas de la nueva era" de la técnica, van a finalizar en la destrucción del hombre:

Habia un gran puente de metal en torno de la tierra

Como los anillos construidos en Saturno

Habia ciudades grandes como un país

Gigantescas ciudades del porvenir

En donde el hombre-hormiga será una cifra.

Nueva desilusión que acrecienta la amargura.

"Una única esperanza - la última esperanza" la ve en el triunfo de la revolución marxista:

Mirad esas estepas que sacuden las manos

Millones de obreros han comprendido al fin

$Y$ levantan al cielo banderas de aurora

Venid, venid os esperamos porque sois la esperanza

La única esperanza

La última esperanza.

Más tarde abrazará las doctrinas marxistas. Basta recordar la "Elegía a la muerte de Lenin" (1924) para sentir más de cerca el fervor del poeta, bastante hiperbólico por cierto. Su lectura nos ha hecho pensar en los ditirambos nerudianos de Las Uvas y el Viento. Poseído de una exaltación pasional ve cómo "selvas y ríos vienen en peregrinación. - Y los países se arrodillan... El ruido de los ma- 
res - se confunde con el canto de las multitudes". Lenin según el pensamiento lírico de Huidobro:

Podrias decir desde la muerte

Estrellas yo puse en marcha a los hombres.

Eres el ruido de una aurora que se levanta...

\section{PERO “ALTAZOR” SIGUE ANGUSTIADO}

Hay momentos de hondas palpitaciones vitales, de anhelos incontenibles de tomar altura para eternizarse y liberarse de la muerte. Pero ya sea que mire a su derredor o ausculte las profundidades de su ser, ve con amargura y pesimismo, cómo se desvanece la esperanza.

Soy una orquesta trágica

Un concepto trágico

Soy trágico como los versos que punzan en las sienes y no [pueden salir.

Matemática fatal y sin esperanza alguna

Capas superpuestas de dolor misterioso

Capas superpuestas de ansias mortales

Subsuelo de intuiciones fabulosas.

Altazor va llegando al final de su meditación existencial en la que la razón lo encierra en la tenebrosa prisión de esta "matemática fatal".

Recojamos en una síntesis las cantidades que se suman y cuyo resultado será una "paradoja fatal", un Altazor con "un pecho que grita y un cerebro que sangra" "un temblor de tierra", "un concepto trágico" de sí mismo, "un animal metafísico cargado de congojas", "un animal espontáneo directo sangrando sus problemas", "una voz del hombre que resuena en los cielos y que pide cuentas de por qué y para qué", "un desmesurado cósmico" con su ideal deshecho y para quien están cerradas todas las puertas. 


\section{LA MUJER}

"No hay bien, no hay mal ni verdad ni orden ni belleza". Esta cadena de negaciones que bien pudiera ser el término del Canto I se ilumina de pronto en el Canto II.

Mujer el mundo está amoblado por tus ojos

Se hace más alto el cielo en tu presencia

La tierra se prolonga de rosa en rosa

$Y$ el aire se prolonga de paloma en paloma.

"Adán" en su soledad paradisíaca, con "campos lozanos" y con "tierra cordial y amistosa", entonó también un himno a Eva en la que

Estaban todas las armonias del mundo

todas las lineas en un éxtasis puro,

todas las misteriosas maravillas

de lo más grande $y$ de lo más oculto.

En su cuerpo vibraban y surgían

todos los hondos secretos del mundo.

La tonalidad poética en ambos casos es diferente. En "Adán”, Eva es un complemento vital, aquí es la tabla de salvación arrojada desde lejos a un náufrago, "solitario como una paradoja".

De ahí que el poeta la ensalce como quien saluda enardecido la luz en la noche tenebrosa de un desierto desconocido.

Su lirismo creacionista empieza tomar altura y la mujer adquiere proyecciones cósmicas para poder así expresar su admiración, su éxtasis que lo arrastra hasta el paroxismo.

Estamos frente a un proceso de "divinización".

Altazor la ve ante sí como "dadora de infinito", como la única que tiene "sabor de eternidad". Eso es precisamente lo que busca. 
No sabe si ella es "la eternidad", pero tiene "sabor de eternidad" y eso le basta.

Huidobro con intuición de auténtico artista conduce la acción dramática de su héroe hasta el lindero del amor humano, para que satisfaga en parte sus ardientes anhelos. Aunque sea un espejismo no importa. Un perdido en el desierto se aferra a él por un instante siquiera, porque es una esperanza. Y Altazor la busca con pasión.

De ahí que los acordes sean sonoros y que la música de estos trozos lleve el ritmo del vértigo.

Mi alegría es oir el ruido del viento on tus cabellos (Reconozco ese ruido desde lejos)

Cuando las barcas zozobran y el río arrastra troncos de árbol Eres una lámpara de carne en la tormenta

Con los cabellos a todo viento

Tus cabellos donde el sol va a buscar sus mejores sueños

Mi alegría es mirarte solitaria sobre el diván del mundo...

Una bebida de paroxismo

Tus ojos hipnotizan la soledad

Como la rueda que sigue girando después de la catástrofe.

¿Por qué la mujer "tiene sabor a eternidad"?

Huidobro es poeta de insondables profundidades. Conoce los resortes y mecanismos ocultos del alma humana y sabe que el "AMOR", así con mayúscula, es un "lenitivo" que amortigua en parte el dolor y los quemantes interrogantes existenciales que atormentan a su héroe. El amor "tiene sabor a eternidad".

En la plenitud de su posesión huyen el tiempo y el espacio. Los amantes nadan sumergidos en el éxtasis que no transcurre. Es entonces cuando se "palpa un infinito" tangible y real, que embriaga al ser total en una dicha descarnada, sin bajezas, sin límites.

El amor llena la "enorme soledad" de Altazor y puede exclamar: 
Nada tiene entonces semejante emoción

$\mathrm{Ni}$ un mástil pidiendo viento

$\mathrm{Ni}$ un aeroplano ciego palpando el infinito

Ni la paloma demacrada dormida sobre un lamento

$\mathrm{Ni}$ el arco iris con las alas selladas

Más bello que la parábola de un verso

La parábola tendida en puente nocturno de alma en alma.

Cuando leemos este poema el pensamiento vuela con insistencia a su otra creación, "Adán”. Es el grito de triunfo o lamento angustiado, cuyo eco se repite en el abismo y se pierde en la lejanía. Allá también está el "Amor" como complemento de otro héroe de Huidobro:

Amor, padre de toda maravilla $y$ de todas las cosas trascendentes:

eje de todos los actos de la vida causa y fuerza que impele todo lo grande.

No debe extrañarnos, pues, el "valor absoluto" del ídolo deidificado" (Goic, página 226) que hallamos en "Altazor".

Las llanuras se pierden bajo tu gracia frágil

Se pierde el mundo bajo tu andar visible

Pues todo es artificio cuando tú te presentas

Con tu luz peligrosa

Inocente armonia sin fatiga ni olvido

Elemento de lágrima que rueda hacia adentro

Construido de miedo altivo $y$ de silencio

Haces dudar al tiempo

$Y$ al cielo con instintos de infinito

Lejos de ti todo es mortal

Lanzas la agonía por la tierra humillada de noches

Sólo lo que piensa en ti tiene sabor a eternidad. 
De "deidificación de la mujer" es un nuevo substituto de Dios.

En Magallanes Moure la amada es claridad en la que Dios se presenta, aunque sea como simple aspiración del poeta. Aquí no. En su concepción atea viene ella a llenar un vacío con la proximidad de su cuerpo y de su espíritu, con todo lo que posee y con todas sus amables sugerencias.

Ella es "más hermosa" "que la sirena de un barco que deja escapar toda su alma".

Entendemos la comparación. El lamento de la sirena procede de sus mismas entrañas, más elocuente cuanto más lastimero. Y Altazor clama desde sus profundidades existenciales. $\mathrm{Y}$ es entonces cuando acude el amor. ¡Cómo no va a ser más hermoso!

Ella es "más hermosa" "que un faro en la neblina buscando a quien salvar". Mientras aquél permanece inmóvil, el Amor se acerca comprensivo, estrecha entre sus brazos, infunde alientos y anima los entumecidos miembros del náufrago.

No nos extrañe que hable así el poeta:

¿Qué sería la vida si no hubieras nacido?

Un cometa sin manto muriéndose de frío...

Si tú murieras

Las estrellas, a pesar de su lámpara encendida

Perderían el camino.

¿Qué sería del Universo?

Huidobro tiende a lo cósmico, como atraído por una fuerza de gravedad. ¿Es sólo un recurso poético? No. En su búsqueda angustiosa de lo infinito trata de liberarse con pasión de los límites que lo aprisionan y su imaginación vaga por las inmensidades del espacio en donde los astros se le asemejan puntos convergentes de realidades ilimitadas. De ahí que frente al amor, encarnado en la mujer, recurra también a la dimensión cósmica integrando su mundo poético con astros, arco iris y estrellas.

Para Goic (página 227) hay un sentido astrológico consciente, 
pero esto no impide relacionarlo con la raíz última de la creación poética, que es a nuestro juicio la anotada más arriba.

He aqui tu estrella que pasa

Con tu respiración de fatigas lejanas

Con tus gestos y tu modo de andar

Con el espacio magnetizado que te saluda

Que nos separa con leguas de noche

Sin embargo te advierto que estamos cosidos

A la misma estrella

Estamos cosidos por la música tendida

De uno a otro...

\section{EL DRAMA DEL CREACIONISMO}

A medida que avanzamos en la lectura de Altazor advertimos que una densa niebla ensombrece de nuevo el panorama de su poesía. El humanismo de tono profético y cósmico que le fue tan característico, tórnase lento y quejumbroso con matices elegíacos e irónicos.

El entierro de la poesía

Todas las lenguas están muertas

Muertas en manos del vecino trágico

Hay que resucitar las lenguas

Con sonoras risas

Con vagones de carcajadas

Con cortacircuitos en las frases

Y cataclismo en la gramática

Levántate $y$ anda

Estira las piernas anquilosis salta.

Este antagonismo nos acerca a lo que llamamos "creacionismo imposible".

Goic se expresa así: 
"La nota me parece una de las más amargas de su poesía y marca junto con un momento de terrible desesperación, una derrota visible de la poesía en su afán creacionista si nos atenemos a la seriedad de sus postulados teóricos en un plano eminentemente humano" (op. cit., página 231).

Anteriormente explicamos brevemente en qué consiste esta “imposibilidad".

El "pequeño dios", a quien Huidobro exigió dimensiones colosales para poder realizar el milagro de "crear, crear, crear", se asombraría ante el pesimismo que encierra este trozo:

$Y$ puesto que debemos vivir y no nos suicidamos

Mientras vivamos juguemos

El simple sport de los vocablos

De la pura palabra y nada más

Sin imagen limpia de joyas

(Las palabras tionen demasiada carga)

Un ritual de vocablos sin sombra

Un juego de ángel allá en lo infinito

Palabra por palabra.

El poeta conjuga aquí el "trágico sentido de la vida", que tanto le atormenta con un desquiciamiento interior en relación con su ideal poético.

El "simple sport de los vocablos" y la "palabra por palabra", suenan a revancha.

Hay pasajes de su poesía que nada dicen, si no es un “juego encubridor y adormecedor de angustias" (Goic, página 235) que están muy lejos de las deslumbradoras concepciones creacionistas.

No vamos a insistir más en este punto, pues roza más bien lo puramente técnico.

Para ilustrar nuestro aserto pongamos un ejemplo: 
Empiece ya

La farandolina en la lejantaña de la montañia

El horimento bajo el firmazonte

Se embarca en la luna

Para dar la vuelta al mundo

Empiece ya

La faranmandó mandó liná

Con su musiqui con su musicá

La carabantina

La carabantantú

La farandolisina

La farandú

La carabantatá

La carabantatí

La farandosilá

La faransí.

Ciertamente que "el pequeño dios" se divierte en "simple juego de sport con los vocablos".

"Altazor" se entretiene, se aturde, mientras llegue el momento de su aniquilamiento definitivo, de su aniquilamiento nihilista. A su lado yace la esperanza hecha trizas.

El análisis de Huidobro en su contenido ideológico se dificulta en sumo grado por su creacionismo.

Es casi imposible seguir los pasos de su pensamiento a través de tantos "lazos sutiles", de tantas "voces secretas", captadas en un éxtasis sin lógica a veces y "separadas por distancias inconmensurables".

En la mayoría de los casos es una maraña densa que obliga por su hermetismo a andar a tientas, expuesto a sabe Dios qué sobresaltos.

El "genio recóndito" que ocultan las palabras, permanece tan oculto que se confunde con las tinieblas. 
Hemos tratado de captar algo de este "genio monstruoso". Su "creacionismo" es un ideal sobrecogedor y tan fuera del alcance humano, que no hemos dudado en llamarlo imposible.

Pero queda en pie una gran verdad: Huidobro encarna el hombre angustiado de nuestro tiempo.

Frente a Dios colocó el Adán Científico, como substituto. Desengañado de la Ciencia se refugió en el amor, pero éste no fue capaz de acallar las voces de su tragedia: la imposibilidad de su creacionismo, drama existencial, ya que simboliza la hecatombe de su ideal.

No creemos haber agotado la materia. Sería una osadía, pero sí confiamos en nuestro esfuerzo por auscultar, a lo menos en líneas generales, algunos aspectos de este creador nuestro, grande entre los grandes.

Las ideas madres analizadas en las páginas anteriores se proyectan hasta el final de sus días.

Temblor de Ciclo (1931), con sus "presagios fatídicos, que desarrollan en él como hogueras voraces o fuegos fatuos", y la muerte en primer plano; Ver y Palpar (1941), con el recuerdo de Altazor, "que jugaba con las golondrinas y los cementerios" y "que se fue de su carne al viento estupefacto", haciendo profesión de fe materialista; El citedadano del Olvido (1941), expresión de un egocentrismo desgarrado, luchando por superar el sentimiento trágico de su existencia ya que es "tierra hacia el espacio" y su "espiritu se hace materia", constituyen las variaciones de un mismo tema.

Lo. mismo acontece con las creaciones postreras recogidas en Ultimos Poemas (1948), obra preparada por su hija Manuela.

La "idea de la muerte" es una meditación con interrogantes cuya respuesta es un lento desintegrarse no para volar a la eternidad sino para volver a la tierra y dar el salto hacia el vacío. 
Yo quiero hablaros de los ojos de la muerte. Del suspiro postrero De las maneras de morir tan distintas como los andares Hijo ¿Qué haces de tu dolor? Los meses van a venir los años, [las Primaveras. Cortejo de sol y cstrellas contando espiritu y variadas voces He puesto mi alma en ese último suspiro y por lo tanto ¿Qué ha de ser de mí?

Tierras sin árboles, corazón sin hierbas ni palomas. ¿Cómo puedes andar entre esperanzas ajenas?

¿Qué voz solemne ha salido de su almendra? ¿Qué canto es ése [que era mio y desconozco? El mar se llena de alma y las rocas escuchas y las arenas no [saben qué hacer ni qué decir. Así se muere. Un airecillo leve entre los dientes, un temblor en los [pétalos

un reflejo de rocío extrahumano en

los cabellos dolorosos y resignados.

Y para finalizar esta búsqueda sincera y también, por qué no decirlo, emocionada del postrer anhelo de este "gigante de nuestra lírica", transcribamos con dolor los postreros acentos de La poesía es un atentado celeste, poema en que Huidobro hace su última profesión de fe materialista:

Angustioso lamentable

Me voy adentrando en estas plantas

Voy dejando mis ropas

Se me van cayendo las carnes

Y mi esqueleto se va revistiendo de cortezas

Me voy haciendo árbol. Cuántas veces me he ido convirtiendo [en otras cosas...

Es doloroso y lleno de ternura. 
El 2 de enero de 1948 murió este hijo de "Adán" que en sus primeros años adoró a Dios, que en su vida fue "Altazor" y que al final de sus días recitó los versos del "Adán Científico":

Entrad, en mí, Naturaleza,

entrad en mí joh cosas de la tierra!

Dejad que yo os adquiera

dadme la suprema alegría

de haceros substancia mía.

Todo esto que nace en el suelo

quiero sentirlo dentro. 